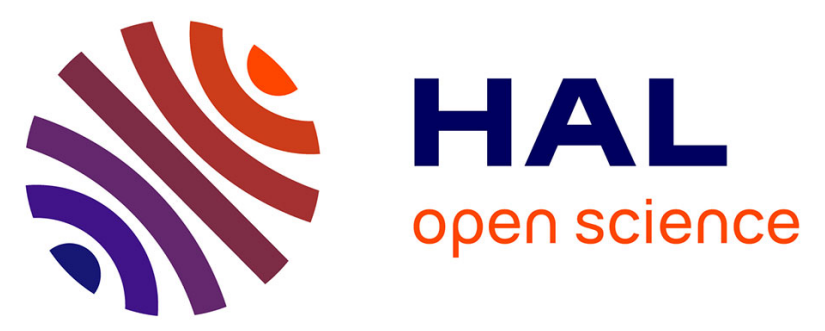

\title{
Feasibility and Effectiveness of Prone Position in Morbidly Obese Patients With ARDS
}

Audrey de Jong, Nicolas Molinari, Mustapha Sebbane, Albert Prades, Emmanuel Futier, Boris Jung, Gerald Chanques, Samir Jaber

\section{To cite this version:}

Audrey de Jong, Nicolas Molinari, Mustapha Sebbane, Albert Prades, Emmanuel Futier, et al.. Feasibility and Effectiveness of Prone Position in Morbidly Obese Patients With ARDS. Chest, 2013, 6, pp.1554-1561. 10.1378/chest.12-2115 . hal-02549932

\section{HAL Id: hal-02549932 \\ https://hal.umontpellier.fr/hal-02549932}

Submitted on 21 Apr 2020

HAL is a multi-disciplinary open access archive for the deposit and dissemination of scientific research documents, whether they are published or not. The documents may come from teaching and research institutions in France or abroad, or from public or private research centers.
L'archive ouverte pluridisciplinaire HAL, est destinée au dépôt et à la diffusion de documents scientifiques de niveau recherche, publiés ou non, émanant des établissements d'enseignement et de recherche français ou étrangers, des laboratoires publics ou privés. 


\title{
Feasibility and Effectiveness of Prone Position in Morbidly Obese Patients With ARDS
}

\section{A Case-Control Clinical Study}

\author{
Audrey De Jong, MD; Nicolas Molinari, PhD; Mustapha Sebbane, MD; \\ Albert Prades, Nursing Fellow; Emmanuel Futier, MD; Boris Jung, MD; \\ Gérald Chanques, MD; and Samir Jaber, $M D$
}

\begin{abstract}
Background: Obese patients are at risk for developing atelectasis and ARDS. Prone position (PP) may reduce atelectasis, and it improves oxygenation and outcome in severe hypoxemic patients with ARDS, but little is known about its effect in obese patients with ARDS.

Methods: Morbidly obese patients $\left(\mathrm{BMI} \geq 35 \mathrm{~kg} / \mathrm{m}^{2}\right)$ with ARDS $\left(\mathrm{PaO}_{2} / \mathrm{FIO}_{2}\right.$ ratio $\left.\leq 200 \mathrm{~mm} \mathrm{Hg}\right)$ were matched to nonobese $\left(B M I<30 \mathrm{~kg} / \mathrm{m}^{2}\right)$ patients with ARDS in a case-control clinical study. The primary end points were safety and complications of PP; the secondary end points were the effect on oxygenation $\left(\mathrm{PaO}_{2} / \mathrm{FIO}_{2}\right.$ ratio at the end of $\left.\mathrm{PP}\right)$, length of mechanical ventilation and ICU stay, nosocomial infections, and mortality.

Results: Between January 2005 and December 2009, 149 patients were admitted for ARDS. Thirtythree obese patients were matched with 33 nonobese patients. Median (25th-75th percentile) PP duration was $9 \mathrm{~h}(6-11 \mathrm{~h})$ in obese patients and $8 \mathrm{~h}(7-12 \mathrm{~h})$ in nonobese patients $(P=.28)$. We collected 51 complications: 25 in obese and 26 in nonobese patients. The number of patients with at least one complication was similar across groups $(n=10,30 \%)$. $\mathrm{Pao}_{2} / \mathrm{FIO}_{2}$ ratio increased significantly more in obese patients (from $118 \pm 43 \mathrm{~mm} \mathrm{Hg}$ to $222 \pm 84 \mathrm{~mm} \mathrm{Hg}$ ) than in nonobese patients (from $113 \pm 43 \mathrm{~mm} \mathrm{Hg}$ to $174 \pm 80 \mathrm{~mm} \mathrm{Hg} ; P=.03$ ). Length of mechanical ventilation, ICU stay, and nosocomial infections did not differ significantly, but mortality at 90 days was significantly lower in obese patients $(27 \%$ vs $48 \%, P<.05)$.

Conclusions: PP seems safe in obese patients and may improve oxygenation more than in nonobese patients. Obese patients could be a subgroup of patients with ARDS who may benefit the most of PP.
\end{abstract}

Abbreviations: $\mathrm{FRC}=$ functional residual capacity; $\mathrm{PP}=$ prone position

$\mathbf{O}$ besity is a global health-care problem, and it is now routine to be confronted with both medical and surgical obese patients in ICUs. Obese patients are at risk for developing ARDS.1,2 The prone position (PP) has been shown to improve respiratory mechanical

Affiliations: From the Intensive Care Unit and Transplantation Department (DAR B) (Drs De Jong, Sebbane, Futier, Jung, Chanques; Prof Jaber; and Mr Prades), Saint Eloi Hospital, University Hospital of Montpellier-INSERM U1046; and the Medical and Informatic Department (Dr Molinari), Lapeyronie University Hospital of Montpellier, UMR 729 MISTEA, Route de Ganges, Montpellier cedex 5, France.

Funding/Support: This study was supported by the University Hospital of Montpellier. and arterial oxygenation in patients with ARDS $^{3-13}$ : Lung inflation is more homogeneously distributed along the dorsoventral axis of the lung with a decrease in ventilation perfusion inequalities, ${ }^{14,15}$ the expiratory time constant is reduced, ${ }^{16}$ and respiratory system compliance and functional residual capacity (FRC) are increased. ${ }^{9}$

Correspondence to: Prof Samir Jaber, Unité de RéanimationDépartement d'Anesthésie-Réanimation "B”, University hospital, CHU de Montpellier Hopital Saint Eloi, 80, Avenue Augustin Fliche, 34295 Montpellier cedex 5, France; e-mail: s-jaber@ chu-montpellier.fr 
Recently, studies have suggested that when initiated early and applied for a long period (ie, 12-20 h), PP might reduce mortality in selected patients with severe ARDS. ${ }^{14,15,17-19}$

Obese patients seem more likely to respond to PP, which may relieve the decreased FRC due, in part, to increased abdominal pressure. Effects of PP have only been reported in obese patients anesthetized for surgical procedures for short periods (ie, $<3 \mathrm{~h})^{20}$ and in one case report. ${ }^{21}$ Although PP has been used for several years to treat acute lung injury, ARDS, or both, to our knowledge use of PP for long period in a large cohort of morbidly obese patients hospitalized in the ICU for ARDS has never been reported. We performed this study to investigate if PP is a safe and useful treatment in obese patients with ARDS. The primary end point was the rate of complications of PP and the secondary end points were the effect on gas exchange, nosocomial infection rate, and mortality.

\section{Materials AND Methods}

\section{Study Design}

Because of the strictly observational, noninterventional study design, which was an evaluation of the routine use of PP in an ICU, and because of the absence of modification in patient clinical management, the need for written consent was waived according to French law. ${ }^{22}$ The local scientific and ethics committee of Comite d'Organization et de Gestion de l'Anesthesie-Reanimation du Centre Hospitalier Universitaire de Montpellier approved the design of the study (project approval number: COGAR-No. 2011-04)
From January 1, 2005, to December 1, 2009, a retrospective, matched-pair, case-control study was conducted in a medicalsurgical and transplantation unit of 16 beds, which is part of an obesity center at the Montpellier University Hospital, St Eloi, Montpellier, France. Demographic data, monitoring variables, and severity score were prospectively recorded in our ICU database (CareVue software; Royal Philips Electronics NV). Then, we performed a retrospective analysis of prospectively collected data.

\section{Patients and Selection of Matched Control Subjects}

Morbidly obese patients defined by a BMI $\geq 35 \mathrm{~kg} / \mathrm{m}^{2}$ were selected if they received invasive mechanical ventilation and fulfilled the diagnostic criteria of $\mathrm{ARDS},{ }^{23}$ that is, a $\mathrm{PaO}_{2} / \mathrm{FIO}_{2}$ ratio $\leq 200 \mathrm{~mm} \mathrm{Hg}$ as assessed with a blood gas analysis performed with at least $5 \mathrm{~cm} \mathrm{H}_{2} \mathrm{O}$ of positive end-expiratory pressure, radiographic evidence of bilateral pulmonary infiltrates, and no evidence of increased pulmonary venous pressure.

The matching procedure was identical to that used in previous studies. ${ }^{24,25}$ Obese patients (BMI $\left.\geq 35 \mathrm{~kg} / \mathrm{m}^{2}\right)$ with a diagnosis of ARDS were matched to nonobese patients (BMI $<30 \mathrm{~kg} / \mathrm{m}^{2}$ ) with ARDS, according to the following five criteria: age \pm 10 years, sex, Simplified Acute Physiology Score II \pm 7 , admission time to ICU \pm 12 months, and type of admission (surgical or medical).

\section{Clinical Management}

PP was used in the early phase of ARDS (ie, $<48 \mathrm{~h}$ of the ARDS course). PP was routinely used in patients with $\mathrm{PaO}_{2} / \mathrm{FIO}_{2}$ ratio $<150 \mathrm{~mm} \mathrm{Hg}$, and in the other cases it was prescribed at the discretion of physicians in charge. Patients were not turned over in PP if they had evidence of cerebral edema or intracranial hypertension, fractures of the spine, or severe hemodynamic instability. The PP session was planned to last from 6 to $18 \mathrm{~h} / \mathrm{d}$ according to the prescription of the physician in charge and was continued until patients were ventilated with a $\mathrm{FIO}_{2}<60 \%$. The $\mathrm{PP}$ usually required

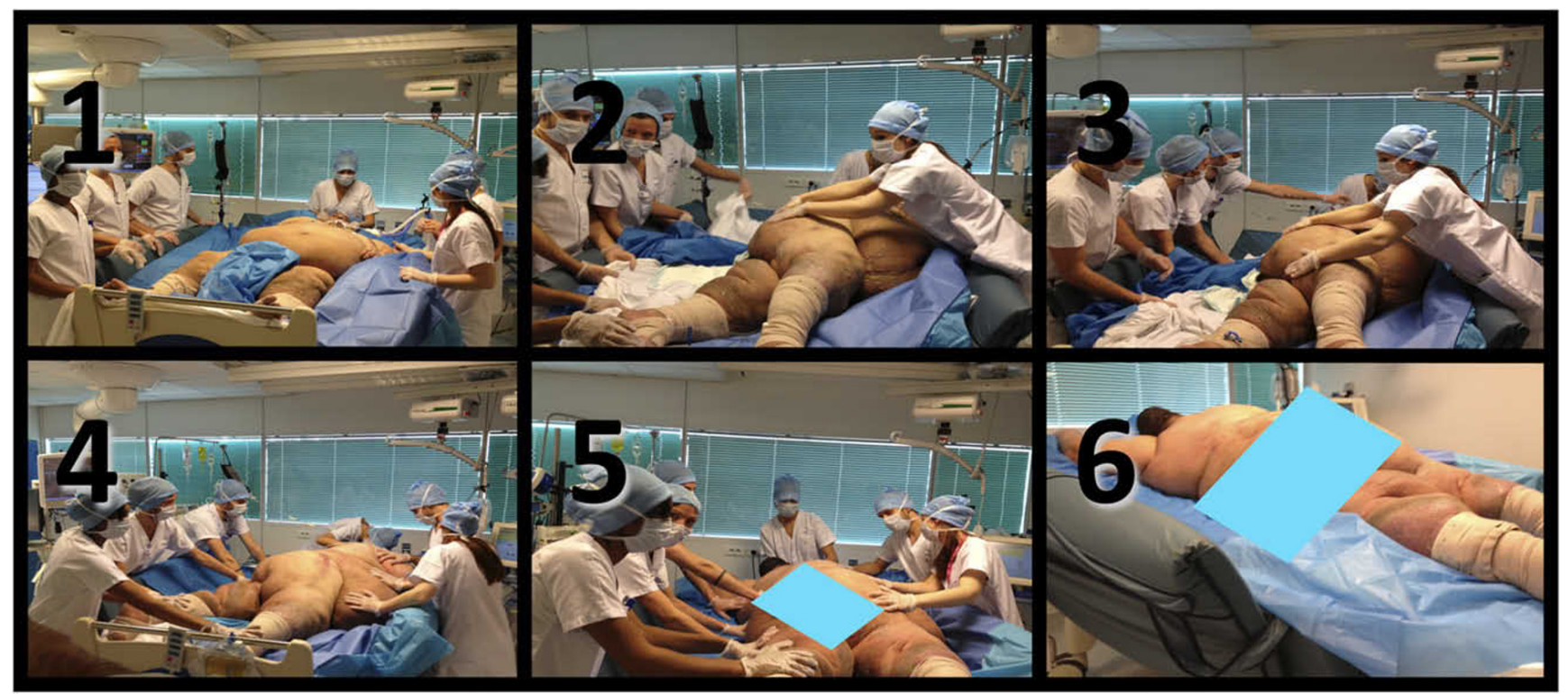

FIGURE 1. Steps of switch from supine to prone position in an obese patient. Step 1, The patient is lying down, under deep sedation and analgesia (Richmond Agitation and Sedation Scale score: -5 , Behavioral Pain Scale score, 3). One operator is at the head of the patient to secure the airway access, three operators are on the right, two on the left, and one is moving to help the others. Step 2, Before starting the procedure, the monitor is checked. The patient is then turned on the left side first. Step 3, Then, the patient is moved to the other side of the bed to prepare for turning. Step 4, The patient is turned in to the prone position. Step 5, Upper chest and pelvic supports are placed to ensure free abdominal movements. Step 6. Finally, the patient is prone positioned, with a regular checking of compression points, and the head is turned every $2 \mathrm{~h}$. (The patient provided written consent for the use of this photograph.) 
Table 1-Main Characteristics of the 104 Patients With ARDS Who Were Proned Before the Matching Selection

\begin{tabular}{|c|c|c|c|c|}
\hline Variables & All Patients ( $\mathrm{N}=104)$ & Obese Patients $(\mathrm{n}=35)$ & Nonobese Patients $(\mathrm{n}=69)$ & $P$ Value \\
\hline Age, y & $59 \pm 15$ & $55 \pm 14$ & $62 \pm 14$ & .02 \\
\hline Male sex, No. (\%) & $76(73)$ & $22(63)$ & $54(78)$ & .09 \\
\hline SAPS II & $46 \pm 15$ & $47 \pm 15$ & $46 \pm 14$ & .30 \\
\hline \multicolumn{5}{|l|}{ Type of admission, No. (\%) } \\
\hline Surgical & $42(40)$ & $19(54)$ & $23(33)$ & .04 \\
\hline Medical & $62(60)$ & $16(46)$ & $46(67)$ & .04 \\
\hline Height, cm & $172 \pm 9$ & $172 \pm 11$ & $171 \pm 8$ & .55 \\
\hline Weight, kg & $89 \pm 29$ & $118 \pm 30$ & $74 \pm 15$ & .01 \\
\hline $\mathrm{BMI}, \mathrm{kg} / \mathrm{m}^{2}$ & $29 \pm 8$ & $38 \pm 5$ & $25 \pm 5$ & .01 \\
\hline \multicolumn{5}{|l|}{ Cause of ARDS, No. (\%) } \\
\hline Pneumonia & $46(44)$ & $12(34)$ & $34(49)$ & .15 \\
\hline Sepsis & $43(41)$ & $18(52)$ & $25(36)$ & .14 \\
\hline Acute pancreatitis & $5(5)$ & $1(3)$ & $4(6)$ & .66 \\
\hline Severe trauma & $10(10)$ & $4(11)$ & $6(9)$ & .73 \\
\hline Patients with at least one complication, No. (\%) & $29(28)$ & $11(31)$ & $18(26)$ & .57 \\
\hline \multicolumn{5}{|l|}{$\mathrm{PaO}_{2} / \mathrm{FIO}_{2}$ ratio, $\mathrm{mm} \mathrm{Hg}$} \\
\hline Before PP & $119 \pm 56$ & $116 \pm 52$ & $120 \pm 60$ & .32 \\
\hline After PP & $195 \pm 88^{a}$ & $209 \pm 94^{\mathrm{a}}$ & $180 \pm 82^{\mathrm{a}}$ & .07 \\
\hline Mortality at day 90, No. (\%) & $39(38)$ & $7(20)$ & $32(46)$ & .02 \\
\hline
\end{tabular}

Data are presented as mean \pm SD unless otherwise indicated. $\mathrm{PP}=$ prone position; SAPS $=$ Simplified Acute Physiology Score.

a $P<.01$, before vs after PP.

a team of four to five people for nonobese patients (three to four rotated the patient and one provided ventilator assistance) and five to six people for obese patients (four to five rotated the patient and one provided ventilator assistance). The head and the neck protruded from the sheet surface to allow proper management of the airway. An inverse Trendelenburg position was applied to decrease facial edema. Attention was paid to avoid any eye damage and nonphysiologic movements of the limbs during posture change (Fig 1).

Extensive descriptions of clinical management and collection of data are provided in e-Appendix 1. Responders to PP were defined as "responders" or "strong responders" if the $\mathrm{PaO}_{2} / \mathrm{FIO}_{2}$ ratio increased by at least $20 \%$ or $40 \%$, respectively.

\section{Statistical Analysis}

The results are expressed as mean $\pm \mathrm{SD}$, median (25th-75th percentile), number of positive results, and percentages. The results of the obese group were compared with those of the nonobese group using the Student $t$ test for quantitative Gaussian variables, the Wilcoxon rank-sum test for the non-Gaussian variables, and the $\chi^{2}$ test for qualitative variables. A Kaplan-Meier analysis was performed to determine the survival lifetimes and a log-rank test was used to compare the two curves (obese group vs nonobese group). The hazard ratio of mortality between obese and nonobese patients was obtained by the Cox method. The statistical analysis was performed by the medical statistical department of the Montpellier University Hospital with the help of statistical software (SAS version 9.3; SAS Institute Inc). Statistical methods used are detailed in e-Appendix 1 . A $P$ value $<0.05$ was considered statistically significant.

\section{RESULTS}

\section{Patient Characteristics}

From January 2005 to December 2009, 2,543 patients were admitted to the ICU. Invasive mechanical ventilation was performed in 1,704 patients; 149 met
ARDS criteria, and of these, 44 were obese and 105 were not. Thirty-five obese patients and 69 nonobese patients were turned to PP. Table 1 presents the main characteristics of the 104 patients with ARDS in whom PP was used before the matching selection. Among them, 33 obese and 60 nonobese patients were eligible for the matching process. Thirty-three patients

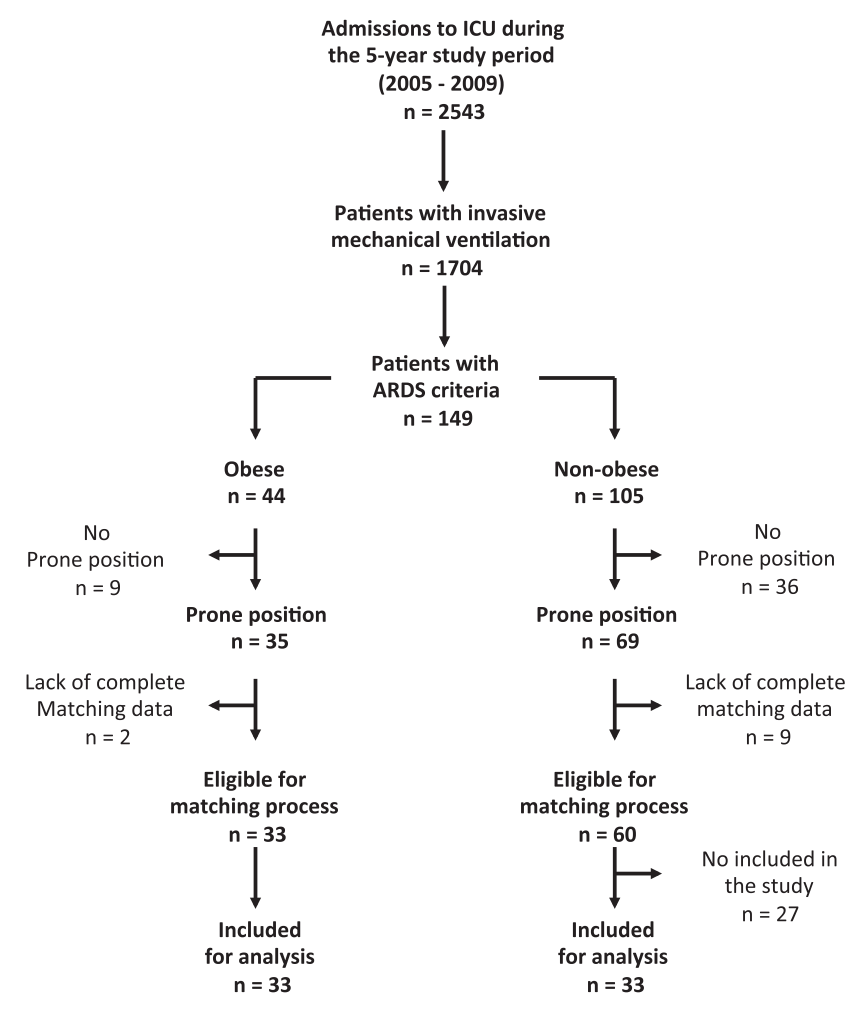

Figure 2. Flow diagram of study participants. 
Table 2-Baseline Study Characteristics of Obese and Nonobese Patients

\begin{tabular}{|c|c|c|c|c|}
\hline Variables & All Patients $(\mathrm{N}=66)$ & Obese Patients $(\mathrm{n}=33)$ & Nonobese Patients $(\mathrm{n}=33)$ & $P$ Value \\
\hline Age, $y$ & $58 \pm 14$ & $55 \pm 14$ & $61 \pm 14$ & .11 \\
\hline Male sex, No. (\%) & $46(70)$ & $22(67)$ & $24(73)$ & .79 \\
\hline SAPS II & $45 \pm 16$ & $48 \pm 15$ & $45 \pm 17$ & .62 \\
\hline \multicolumn{5}{|c|}{ Type of admission, No. (\%) } \\
\hline Surgical & $33(50)$ & $18(55)$ & $15(45)$ & .62 \\
\hline Medical & $33(50)$ & $15(45)$ & $18(55)$ & .62 \\
\hline Height, cm & $171 \pm 10$ & $173 \pm 11$ & $170 \pm 8$ & .22 \\
\hline Weight, kg & $95 \pm 32$ & $116 \pm 28$ & $72 \pm 13$ & .01 \\
\hline BMI, $\mathrm{kg} / \mathrm{m}^{2}$ & $32 \pm 9$ & $38 \pm 7$ & $25 \pm 4$ & .01 \\
\hline Body surface, $\mathrm{m}^{2}$ & $1.92 \pm 0.58$ & $2.27 \pm 0.29$ & $1.45 \pm 0.55$ & .01 \\
\hline \multicolumn{5}{|c|}{ Cause of ARDS, No. (\%) } \\
\hline Pneumonia & $31(47)$ & $12(36)$ & $19(58)$ & .14 \\
\hline Sepsis & $27(41)$ & $17(52)$ & $10(30)$ & .13 \\
\hline Acute pancreatitis & $3(5)$ & $1(3)$ & $2(6)$ & 1.00 \\
\hline Severe trauma & $5(7)$ & $3(9)$ & $2(6)$ & 1.00 \\
\hline
\end{tabular}

Data are presented as mean \pm SD unless otherwise indicated. See Table 1 legend for expansion of abbreviation.

were included for analysis in each group. Figure 2 shows the flow diagram of the study. e-Table 1 summarizes the effectiveness of matching, patient by patient. Eighty-three percent of criteria (137 of 165) were correctly matched.

Baseline demographic characteristics at admission and main causes of ARDS did not differ significantly between groups (Table 2). Only one patient in the obese group was dialyzed during PP, using continuous venovenous hemodiafiltration. During PP, no significant difference was observed between obese and nonobese patients for enteral feeding ( $15 \%$ vs $25 \%$; $P=.32)$, nasogastric-tube use ( $67 \%$ vs $64 \% ; P=.80)$, vasoactive-drug use $(51 \%$ vs $64 \% ; P=.32)$; and myorelaxant use (36\% vs $48 \% ; P=.32)$.

\section{Characteristics of PP and Related Complications}

Overall, for the 66 evaluated patients, 211 sessions of PP were studied (122 for obese and 89 for obese patients), corresponding to $1,838 \mathrm{~h}(1,021 \mathrm{~h}$ for obese and $817 \mathrm{~h}$ for nonobese patients). The characteristics of PP are shown in Table 3. The median PP length did not differ significantly between the two groups $(P=.28)$.

Of the 66 evaluated patients, 20 experienced at least one complication, with no significant difference between groups ( 10 of 33 for both; $P=1.00$ ). Table 3 reports the complications observed during the study. Compared with patients with at least one complication, those without complications had shorter total PP duration (median: 18 h [10-31] vs 35 h [16-54];

Table 3-Characteristics and Complications of PP in Obese and Nonobese Patients

\begin{tabular}{|c|c|c|c|c|}
\hline Variable & All Patients $(\mathrm{N}=66)$ & Obese Patients $(\mathrm{n}=33)$ & Nonobese Patients $(\mathrm{n}=33)$ & $P$ Value \\
\hline Total number of sessions by patient & $2(1-4)$ & $3(2-4)$ & $2(1-3)$ & .16 \\
\hline Total length of PP by patient, $\mathrm{h}$ & $22(10-37)$ & $28(14-42)$ & $16(9-30)$ & .34 \\
\hline Length per session by patient, $\mathrm{h}$ & $8(7-11)$ & $9(6-11)$ & $8(7-12)$ & .28 \\
\hline Patients with at least one complication, No. (\%) & $20(30)$ & $10(30)$ & $10(30)$ & $\ldots$ \\
\hline Overall complications, No. & 51 & 25 & 26 & $\ldots$ \\
\hline Accidental extubation & 1 & 1 & 0 & $\ldots$ \\
\hline Displacement of endotracheal tube & 0 & 0 & 0 & $\ldots$ \\
\hline Loss of venous access & 1 & 0 & 1 & $\ldots$ \\
\hline Loss of arterial access & 0 & 0 & 0 & $\ldots$ \\
\hline Loss of urinary catheter & 0 & 0 & 0 & $\ldots$ \\
\hline Loss of gastric tube & 0 & 0 & 0 & $\ldots$ \\
\hline Forehead pressure ulcers & 5 & 4 & 1 & $\ldots$ \\
\hline Chin pressure ulcers & 10 & 4 & 6 & $\ldots$ \\
\hline Other pressure ulcers & 6 & 3 & 3 & $\ldots$ \\
\hline Total pressure ulcers & 16 & 7 & 9 & $\ldots$ \\
\hline Facial edema & 8 & 4 & 4 & $\ldots$ \\
\hline Hemodynamic failure & 0 & 0 & 0 & $\ldots$ \\
\hline Cardiac arrest & 2 & 1 & 1 & $\ldots$ \\
\hline Bleeding & 1 & 1 & 0 & $\ldots$ \\
\hline Vomiting & 1 & 0 & 1 & $\ldots$ \\
\hline
\end{tabular}

Data are presented as median (25th-75th percentile) unless otherwise indicated. See Table 1 legend for expansion of abbreviation. 
$P=.003)$ and fewer number of sessions (median:

$2[1-3]$ vs $4[2-6] ; P=.04)$.

\section{Outcome}

Table 4 shows the baseline values of the main respiratory variables, as well as their change at the end of PP.
In both groups, the $\mathrm{PaO}_{2} / \mathrm{FIO}_{2}$ ratio was significantly increased between supine position and PP $(P<.0001)$. In PP, obese patients had a significantly higher $\mathrm{PaO}_{2} / \mathrm{FIO}_{2}$ ratio than nonobese patients $(P=.03)$, whereas there was no statistical difference in supine position.

Among the 52 patients in whom paired arterial blood gas measurements were obtained before and after

Table 4-Physiologic Variables and Ventilator Settings Before and After PP in Obese and Nonobese Patients

\begin{tabular}{|c|c|c|c|c|}
\hline Variables & All Patients $(\mathrm{N}=66)$ & Obese Patients $(\mathrm{n}=33)$ & Nonobese patients $(\mathrm{n}=33)$ & $P$ Value \\
\hline \multicolumn{5}{|c|}{ Heart rate, beats/min } \\
\hline Before PP & $96 \pm 18$ & $95 \pm 16$ & $97 \pm 20$ & .67 \\
\hline After PP & $92 \pm 21$ & $92 \pm 25$ & $92 \pm 17$ & .87 \\
\hline \multicolumn{5}{|c|}{ Respiratory rate, breaths/min } \\
\hline Before PP & $23 \pm 5$ & $23 \pm 5$ & $24 \pm 5$ & .48 \\
\hline After PP & $24 \pm 5$ & $23 \pm 5$ & $25 \pm 5$ & .18 \\
\hline \multicolumn{5}{|c|}{ Systolic arterial pressure, $\mathrm{mm} \mathrm{Hg}$} \\
\hline Before PP & $122 \pm 23$ & $124 \pm 20$ & $119 \pm 25$ & .35 \\
\hline After PP & $126 \pm 18$ & $127 \pm 18$ & $125 \pm 19$ & .64 \\
\hline \multicolumn{5}{|c|}{ Diastolic arterial pressure, $\mathrm{mm} \mathrm{Hg}$} \\
\hline Before PP & $58 \pm 10$ & $58 \pm 9$ & $58 \pm 11$ & .73 \\
\hline After PP & $60 \pm 9$ & $59 \pm 8$ & $61 \pm 10$ & .50 \\
\hline \multicolumn{5}{|c|}{ Arterial pressure, $\mathrm{mm} \mathrm{Hg}$} \\
\hline Before PP & $80 \pm 11$ & $80 \pm 10$ & $80 \pm 12$ & .92 \\
\hline After PP & $80 \pm 15$ & $78 \pm 16$ & $83 \pm 14$ & .22 \\
\hline \multicolumn{5}{|c|}{ PEEP, $\mathrm{cm} \mathrm{H}_{2} \mathrm{O}$} \\
\hline Before PP & $9 \pm 3$ & $10 \pm 3$ & $9 \pm 2$ & .43 \\
\hline After PP & $10 \pm 3$ & $10 \pm 3$ & $10 \pm 2$ & .37 \\
\hline \multicolumn{5}{|c|}{ Plateau pressure, $\mathrm{cm}_{2} \mathrm{O}$} \\
\hline Before PP & $24 \pm 5$ & $24 \pm 5$ & $24 \pm 9$ & .57 \\
\hline After PP & $23 \pm 4$ & $22 \pm 3$ & $23 \pm 4$ & .58 \\
\hline \multicolumn{5}{|c|}{ Peak inspiratory pressure, $\mathrm{cm} \mathrm{H}_{2} \mathrm{O}$} \\
\hline Before PP & $33 \pm 3$ & $35 \pm 6$ & $32 \pm 3$ & .28 \\
\hline After PP & $32 \pm 4$ & $31 \pm 4$ & $32 \pm 4$ & .60 \\
\hline \multicolumn{5}{|c|}{ Airway pressure, $\mathrm{cm} \mathrm{H}_{2} \mathrm{O}$} \\
\hline Before PP & $17 \pm 3$ & $17 \pm 3$ & $16 \pm 4$ & .89 \\
\hline After PP & $16 \pm 4$ & $15 \pm 3$ & $16 \pm 3$ & .34 \\
\hline \multicolumn{5}{|c|}{ Tidal volume, $\mathrm{mL}$} \\
\hline Before PP & $459 \pm 80$ & $466 \pm 61$ & $451 \pm 97$ & .53 \\
\hline After PP & $451 \pm 77$ & $463 \pm 53$ & $439 \pm 94$ & .24 \\
\hline \multicolumn{5}{|c|}{ Tidal volume per $\mathrm{kg}, \mathrm{mL} / \mathrm{kg}$} \\
\hline Before PP & $7.2 \pm 1.3$ & $7.2 \pm 1.0$ & $7.1 \pm 1.5$ & .68 \\
\hline After PP & $7.0 \pm 1.2$ & $7.2 \pm 1.0$ & $6.9 \pm 1.4$ & .30 \\
\hline \multicolumn{5}{|c|}{ Arterial $\mathrm{pH}$, units } \\
\hline Before PP & $7.38 \pm 0.10$ & $7.36 \pm 0.09$ & $7.39 \pm 0.11$ & .21 \\
\hline After PP & $7.40 \pm 0.08$ & $7.39 \pm 0.07$ & $7.42 \pm 0.08$ & .17 \\
\hline \multicolumn{5}{|c|}{ Alkaline reserve, mmol/L } \\
\hline Before PP & $25 \pm 5$ & $24 \pm 4$ & $26 \pm 5$ & .25 \\
\hline After PP & $25 \pm 5$ & $24 \pm 4$ & $26 \pm 6$ & .07 \\
\hline \multicolumn{5}{|l|}{$\mathrm{PaO}_{2}, \mathrm{~mm} \mathrm{Hg}$} \\
\hline Before PP & $89 \pm 32$ & $92 \pm 33$ & $86 \pm 31$ & .50 \\
\hline After PP & $133 \pm 57^{a}$ & $146 \pm 55^{\mathrm{a}}$ & $122 \pm 57^{\mathrm{a}}$ & .11 \\
\hline \multicolumn{5}{|l|}{$\mathrm{PaCO}_{2}, \mathrm{~mm} \mathrm{Hg}$} \\
\hline Before PP & $43 \pm 11$ & $43 \pm 8$ & $43 \pm 13$ & .84 \\
\hline After PP & $40 \pm 10$ & $39 \pm 7$ & $41 \pm 13$ & .44 \\
\hline \multicolumn{5}{|l|}{$\mathrm{FIO}_{2}, \%$} \\
\hline Before PP & $79 \pm 20$ & $79 \pm 20$ & $79 \pm 20$ & .93 \\
\hline After PP & $68 \pm 14^{\mathrm{a}}$ & $66 \pm 15^{\mathrm{a}}$ & $70 \pm 13^{\mathrm{a}}$ & .28 \\
\hline \multicolumn{5}{|c|}{$\mathrm{PaO}_{2} / \mathrm{FIO}_{2}$ ratio, $\mathrm{mm} \mathrm{Hg}$} \\
\hline Before PP & $115 \pm 42$ & $118 \pm 43$ & $113 \pm 42$ & .70 \\
\hline After PP & $197 \pm 85^{\mathrm{a}}$ & $222 \pm 84^{a}$ & $174 \pm 80^{a}$ & .03 \\
\hline
\end{tabular}

Data are presented as mean \pm SD unless otherwise indicated. See Table 1 legend for expansion of abbreviation. aP $<.01$, before vs after PP. 


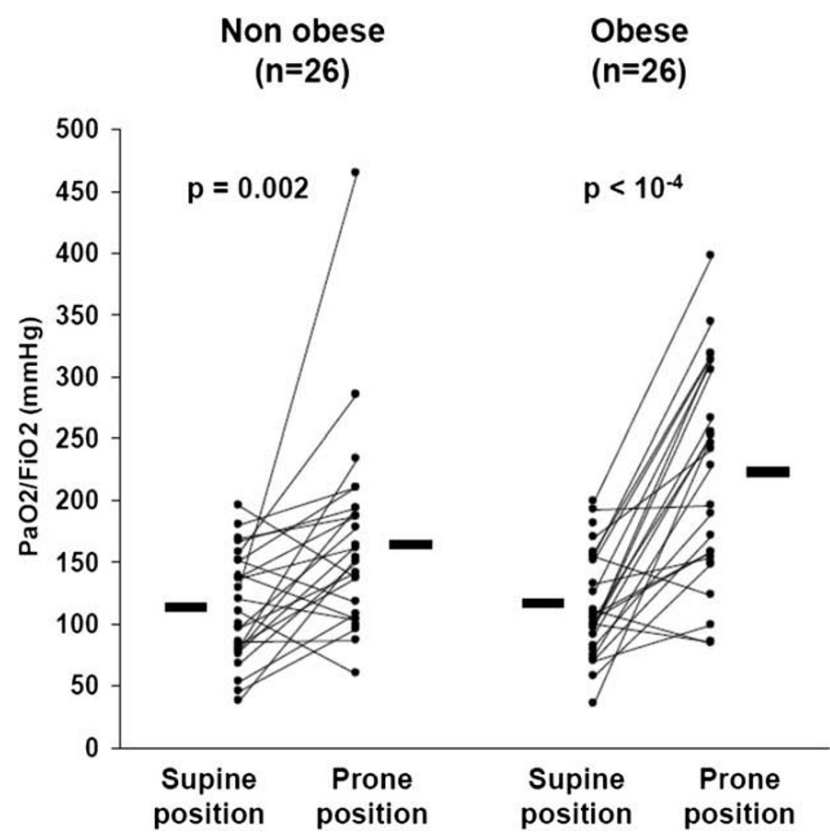

Figure 3. Individual variations of $\mathrm{PaO}_{2} / \mathrm{FIO}_{2}$ ratio between the supine and prone positions in obese and nonobese patients. $\mathrm{PaO}_{2} / \mathrm{FIO}_{2}$ ratio was more improved in the obese group than in the nonobese group ( $+88 \%$ vs $+54 \% ; P=.04)$.

$\mathrm{PP}$, individual $\mathrm{PaO}_{2} / \mathrm{FIO}_{2}$ ratios were more increased in obese patients (118 $\mathrm{mm} \mathrm{Hg}$ to $222 \mathrm{~mm} \mathrm{Hg}$ ) than in nonobese patients $(113 \mathrm{~mm} \mathrm{Hg}$ to $174 \mathrm{~mm} \mathrm{Hg}$; $P=.04)($ Fig 3).

Overall, $71 \%$ of those 52 patients were responders: $81 \%$ of responders ( 21 of 26 ) were obese patients and $62 \%$ (16 of 26 ) were nonobese patients $(P=.22)$. Strong responders, however, were significantly more numerous in the obese group, with 20 responders from the group of $26(77 \%)$ vs 13 of $26(50 \% ; P=.044)$ in the nonobese group.

In the more severe hypoxemic patients, defined by a $\mathrm{PaO}_{2} / \mathrm{FIO}_{2}<100 \mathrm{~mm} \mathrm{Hg}(\mathrm{n}=26$ overall), the $\mathrm{PaO}_{2} / \mathrm{FIO}_{2}$ ratio was significantly higher in $\mathrm{PP}$ than in supine position (180 $\pm 69 \mathrm{~mm} \mathrm{Hg}$ vs $77 \pm 19 \mathrm{~mm} \mathrm{Hg}$; $P<.001)$. Among severe hypoxemic patients, $\mathrm{PaO}_{2} / \mathrm{FIO}_{2}$ increased from $80 \pm 19 \mathrm{~mm} \mathrm{Hg}$ to $206 \pm 77 \mathrm{~mm} \mathrm{Hg}$ in obese patients $(\mathrm{n}=12)$ and from $74 \pm 19 \mathrm{~mm} \mathrm{Hg}$ to $157 \pm 55 \mathrm{~mm} \mathrm{Hg}$ in nonobese patients $(\mathrm{n}=14)$ $(P=.09)$

Table 5 shows the outcome parameters. There was no significant difference across groups except for mortality at 90 days. Figure 4 shows the Kaplan-Meier curves at 90 days in the obese and nonobese groups. Mortality at 90 days was significantly lower in the obese group $(P=.03$; hazard ratio, $0.36 ; 95 \% \mathrm{CI}$, $0.14-0.93)$

\section{Discussion}

The main findings of this study are that obese patients with ARDS can be treated effectively and safely in PP and that this strategy is associated with better outcomes. To our knowledge, it is the first study that specifically reports the routine application of PP in a population of obese patients with ARDS.

Only one case report on an obese patient with ARDS has been published, showing that turning over the patient in PP improved oxygenation. ${ }^{21}$ In previous studies of Mancebo et al, ${ }^{17}$ Fernandez et al, ${ }^{15}$ and Gattinoni et al, ${ }^{13}$ BMI was not reported; in the Guerin et al ${ }^{26}$ study, the mean BMI was $26 \pm 6 \mathrm{~kg} / \mathrm{m}^{2}$.

PP has been regularly performed in our unit since 1997, which could explain the low rate of complications in our study compared with previous ones. ${ }^{27,28}$ Pressure ulcers ranged from $3 \%$ in the Mancebo et al ${ }^{17}$ study to $91 \%$ in the Voggenreiter group's ${ }^{29}$ study. In our study, they were reported in respectively $21 \%$ and $27 \%$ of patients in the obese and nonobese groups. While we recorded facial swelling in $12 \%$ of both groups, facial swelling ranged from $18 \%$ in the Mancebo et al ${ }^{17}$ study to $100 \%$ in the Watanabe et al ${ }^{30}$ study; the less edema seen in our study may be because of the inverse Trendelenburg position we used. We had one cardiac arrest occur in each group $(3 \%)$, similar to that reported in the study by Mancebo and coworkers. ${ }^{17}$ Accidental extubation was only observed in $3 \%$ of our patients. A previous study by Gattinoni et al ${ }^{13}$ had already shown that the percentages of patients with

Table 5-Outcome Parameters in Obese Patients and Nonobese Patients

\begin{tabular}{|c|c|c|c|c|}
\hline Parameters & All Patients $(\mathrm{N}=66)$ & Obese Patients $(\mathrm{n}=33)$ & Nonobese Patients $(\mathrm{n}=33)$ & $P$ Value \\
\hline Nosocomial infections & $37(56)$ & $18(55)$ & $19(58)$ & 1.00 \\
\hline VAP & $22(33)$ & $8(23)$ & $14(42)$ & .19 \\
\hline Central venous catheter & $8(12)$ & $5(9)$ & $3(9)$ & .71 \\
\hline Urinary tract infection & $9(14)$ & $6(18)$ & $3(9)$ & .48 \\
\hline Bacteremia & $15(23)$ & $10(30)$ & $5(15)$ & .24 \\
\hline Length of stay in ICU, mean $\pm \mathrm{SD}, \mathrm{d}$ & $29 \pm 27$ & $25 \pm 35$ & $25 \pm 17$ & 1.00 \\
\hline Duration of mechanical ventilation, mean $\pm \mathrm{SD}, \mathrm{d}$ & $20 \pm 18$ & $16 \pm 22$ & $19 \pm 13$ & .50 \\
\hline Mortality at day 28 & $15(23)$ & $4(12)$ & $11(33)$ & .08 \\
\hline Mortality at day 90 & $21(32)$ & $6(18)$ & $15(45)$ & .02 \\
\hline
\end{tabular}

Data are presented as No. (\%) unless otherwise indicated. VAP = ventilator-associated pneumonia. 


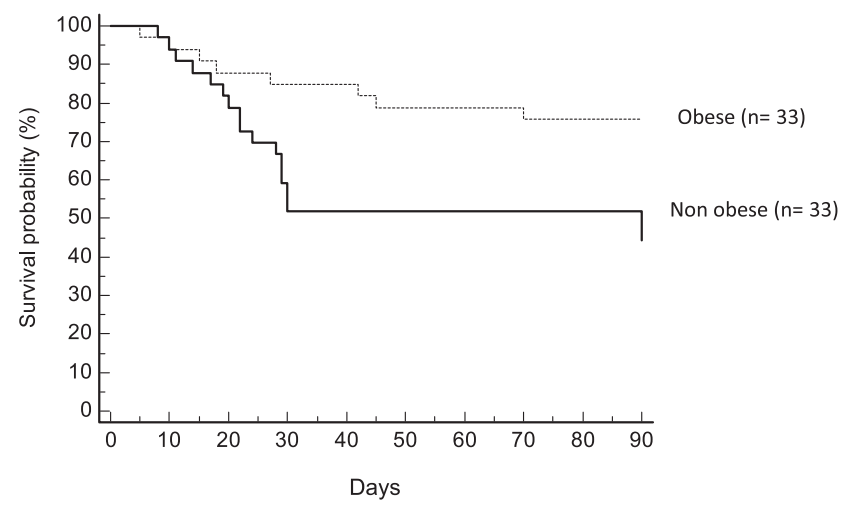

FIGURE 4. The survival curve of obese vs nonobese patients. There was a significant difference in survival curves based on Kaplan-Meier analysis $\left(\chi^{2}=4.9601 ; P=.0259\right)$.

accidental displacement of a tracheal or thoracotomy tube or loss of venous access were not increased in $\mathrm{PP}$ compared with supine position.

$\mathrm{PaO}_{2} / \mathrm{FIO}_{2}$ ratio was more improved in the obese group than in the nonobese group $(+88 \%$ vs $+54 \%$; $P=.04)$. The increase in $\mathrm{PaO}_{2} / \mathrm{FIO}_{2}$ ratio in the nonobese group was similar to other studies. ${ }^{14,31}$

The explanation of the improvement in oxygenation could be physiologic: Ventilation in the PP recruits collapsed regions of the lung without increasing airway pressure or hyperinflation. The delivered tidal volume and peak pressure are dispersed to more alveoli, decreasing the risk of alveolar injury from stretch and strain forces. ${ }^{9}$ This lung-protection effect of PP ventilation could be more important in obese patients because of their decreased FRC and their increased atelectasis. ${ }^{14}$

There tended to be more responders to PP in the obese group, considering a threshold of $20 \%$ increase in $\mathrm{PaO}_{2} / \mathrm{Fio}_{2}$ ratio, which was the threshold most selected in previous studies. ${ }^{31,32}$ When considering a threshold of $40 \%$ increase in $\mathrm{PaO}_{2} / \mathrm{FIO}_{2}$ ratio, the difference was significant, with a higher response in obese than in nonobese patients ( $77 \%$ vs $50 \% ; P=.04)$. The incidences of nosocomial infections and of VAP, in particular, did not differ significantly between groups and was similar to that reported in other ARDS studies. ${ }^{26}$

In the present study, mortality at day 90 in obese patients was low (18\%), with an a Simplified Severity Index II score of 48, and was significantly lower than in nonobese patients (45\%). However, the present study was not designed to evaluate mortality and the number of included patients was limited for any meaningful comparison concerning mortality.

Several issues need to be stated when our results are applied to clinical practice. First, this is a monocenter, unblinded, nonrandomized, observational casecontrol study, which weakens the conclusion that we can draw. We chose to describe our experience with PP management as a current practice in patients with severe ARDS in our ICU, rather than to randomize patients to PP or not PP. However, there was a control group. Second, it is acknowledged that retrospective identification of complications depends on the detail and completeness of the medical record. To minimize this factor, the written transmissions of the physicians, nurses, and nurses' assistants were carefully checked by both medical- (ADJ) and nurse-research (AP) investigators. Third, duration of PP was not standardized, ranging from 1-19 h. However, the median time was not significantly different between obese and nonobese patients. Finally, it is important to emphasize that these results were obtained in a single ICU that is highly experienced in PP therapy. The results may not be so favorable in less experienced centers and deserve further confirmation in other institutions.

In conclusion, we have shown that obese patients with ARDS can be treated effectively and safely in PP. Further randomized, controlled studies are needed to confirm that obese patients with ARDS represent a selected population that may benefit from PP in terms of morbidity and mortality.

\section{ACKNOWLEDGMENTS}

Author contributions: Prof Jaber had full access to all of the data in the study and takes responsibility for the integrity of the data and the accuracy of the data analysis.

Dr De Jong: contributed to data collection, data analysis, drafting and writing the manuscript, and served as principal author.

Dr Molinari: contributed to statistical methods and statistical data analysis, and read and approved the final manuscript.

Dr Sebbane: contributed to data analysis, manuscript review, read and approved the final manuscript.

Mr Prades: contributed to data collection, read and approved the final manuscript.

Dr Futier: contributed to data analysis, manuscript review, read and approved the final manuscript.

Dr Jung: contributed to data collection, manuscript review, read and approved the final manuscript.

Dr Chanques: contributed to data collection, manuscript review, read and approved the final manuscript.

Prof Jaber: contributed to study conception and design, data analysis, revision of the manuscript, and read and approved the final manuscript.

Financial/nonfinancial disclosures: The authors have reported to CHEST that no potential conflicts of interest exist with any companies/organizations whose products or services may be discussed in this article.

Other contributions: The authors are grateful for the enthusiastic support of the doctors, nurses, and assistant nurses of the ICU (DAR B) at Saint-Eloi Montpellier University Hospital. We thank also Valérie Macioce (Statistic Department of Montpellier Hospital) for the English editing.

\section{REFERENCES}

1. Gong MN, Bajwa EK, Thompson BT, Christiani DC. Body mass index is associated with the development of acute respiratory distress syndrome. Thorax. 2010;65(1):44-50.

2. Anzueto A, Frutos-Vivar F, Esteban A, et al; Ventila group. Influence of body mass index on outcome of the mechanically ventilated patients. Thorax. 2011;66(1):66-73.

3. Piehl MA, Brown RS. Use of extreme position changes in acute respiratory failure. Crit Care Med. 1976;4(1):13-14. 
4. Douglas WW, Rehder K, Beynen FM, Sessler AD, Marsh HM. Improved oxygenation in patients with acute respiratory failure: the prone position. Am Rev Respir Dis. 1977;115(4): 559-566.

5. Langer M, Mascheroni D, Marcolin R, Gattinoni L. The prone position in ARDS patients. A clinical study. Chest. 1988;94(1):103-107.

6. Chatte G, Sab JM, Dubois JM, Sirodot M, Gaussorgues P Robert D. Prone position in mechanically ventilated patients with severe acute respiratory failure. Am J Respir Crit Care Med. 1997;155(2):473-478.

7. Blanch L, Mancebo J, Perez M, et al. Short-term effects of prone position in critically ill patients with acute respiratory distress syndrome. Intensive Care Med. 1997;23(10): 1033-1039.

8. Servillo G, Roupie E, De Robertis E, et al. Effects of ventilation in ventral decubitus position on respiratory mechanics in adult respiratory distress syndrome. Intensive Care Med. 1997;23(12):1219-1224.

9. Pelosi P, Tubiolo D, Mascheroni D, et al. Effects of the prone position on respiratory mechanics and gas exchange during acute lung injury. Am I Respir Crit Care Med. 1998;157(2): 387-393.

10. Martinez M, Diaz E, Joseph D, et al. Improvement in oxygenation by prone position and nitric oxide in patients with acute respiratory distress syndrome. Intensive Care Med. $1999 ; 25(1): 29-36$.

11. Nakos G, Tsangaris I, Kostanti E, et al. Effect of the prone position on patients with hydrostatic pulmonary edema compared with patients with acute respiratory distress syndrome and pulmonary fibrosis. Am J Respir Crit Care Med. 2000; 161(2 Pt 1):360-368.

12. Rialp G, Betbesé AJ, Pérez-Márquez M, Mancebo J. Shortterm effects of inhaled nitric oxide and prone position in pulmonary and extrapulmonary acute respiratory distress syndrome. Am I Respir Crit Care Med. 2001;164(2):243-249.

13. Gattinoni L, Tognoni G, Pesenti A, et al; Prone-Supine Study Group. Effect of prone positioning on the survival of patients with acute respiratory failure. N Engl J Med. 2001;345(8): 568-573.

14. Gattinoni L, Carlesso E, Taccone P, Polli F, Guérin C, Mancebo J. Prone positioning improves survival in severe ARDS: a pathophysiologic review and individual patient meta-analysis. Minerva Anestesiol. 2010;76(6):448-454.

15. Fernandez R, Trenchs X, Klamburg J, et al. Prone positioning in acute respiratory distress syndrome: a multicenter randomized clinical trial. Intensive Care Med. 2008;34(8): 1487-1491

16. Vieillard-Baron A, Rabiller A, Chergui K, et al. Prone position improves mechanics and alveolar ventilation in acute respiratory distress syndrome. Intensive Care Med. 2005;31(2):220-226.

17. Mancebo J, Fernández R, Blanch L, et al. A multicenter trial of prolonged prone ventilation in severe acute respiratory distress syndrome. Am J Respir Crit Care Med. 2006; 173(11):1233-1239.
18. Charron C, Bouferrache K, Caille V, et al. Routine prone positioning in patients with severe ARDS: feasibility and impact on prognosis. Intensive Care Med. 2011;37(5):785-790.

19. Abroug F, Ouanes-Besbes L, Dachraoui F, Ouanes I, Brochard L. An updated study-level meta-analysis of randomised controlled trials on proning in ARDS and acute lung injury. Crit Care. 2011;15(1):R6.

20. Pelosi P, Croci M, Calappi E, et al. Prone positioning improves pulmonary function in obese patients during general anesthesia. Anesth Analg. 1996;83(3):578-583.

21. Chergui K, Choukroun G, Meyer P, Caen D. Prone positioning for a morbidly obese patient with acute respiratory distress syndrome: an opportunity to explore intrinsic positive end-expiratory pressure-lower inflexion point interdependence. Anesthesiology. 2007;106(6):1237-1239.

22. Legifrance.gouv.fr. Law 88-1138 relative to Biomedical Research of December 20, 1988, modified on August 9, 2004. Legifrance website. http://www.legifrance.gouv.fr/affichTexte. do?cidTexte=LEGITEXT000006076580\&dateTexte $=20090729$. Accessed September 30, 2012.

23. Bernard GR, Artigas A, Brigham KL, et al. The AmericanEuropean Consensus Conference on ARDS. Definitions, mechanisms, relevant outcomes, and clinical trial coordination. Am J Respir Crit Care Med. 1994;149(3 pt 1):818-824.

24. Jaber S, Chanques G, Borry J, et al. Cytomegalovirus infection in critically ill patients: associated factors and consequences. Chest. 2005;127(1):233-241.

25. Atkins PM, Mion LC, Mendelson W, Palmer RM, Slomka J, Franko T. Characteristics and outcomes of patients who self-extubate from ventilatory support: a case-control study. Chest. 1997;112(5):1317-1323.

26. Guerin C, Gaillard S, Lemasson S, et al. Effects of systematic prone positioning in hypoxemic acute respiratory failure: a randomized controlled trial. JAMA. 2004;292(19):2379-2387.

27. Pelosi P, Brazzi L, Gattinoni L. Prone position in acute respiratory distress syndrome. Eur Respir J. 2002;20(4):1017-1028.

28. Taccone P, Pesenti A, Latini R, et al; Prone-Supine II Study Group. Prone positioning in patients with moderate and severe acute respiratory distress syndrome: a randomized controlled trial. JAMA. 2009;302(18):1977-1984.

29. Voggenreiter G, Aufmkolk M, Stiletto RJ, et al. Prone positioning improves oxygenation in post-traumatic lung injury-a prospective randomized trial. I Trauma. 2005;59(2):333-341., discussion 341-343.

30. Watanabe I, Fujihara H, Sato K, et al. Beneficial effect of a prone position for patients with hypoxemia after transthoracic esophagectomy. Crit Care Med. 2002;30(8):1799-1802.

31. Papazian L, Paladini MH, Bregeon F, et al. Is a short trial of prone positioning sufficient to predict the improvement in oxygenation in patients with acute respiratory distress syndrome? Intensive Care Med. 2001;27(6):1044-1049.

32. Mebazaa M-S, Abid N, Frikha N, Mestiri T, Ben Ammar M-S The prone position in acute respiratory distress syndrome: a critical systematic review [in French]. Ann Fr Anesth Reanim. 2007;26(4):307-318 